\title{
EFFECT OF COMPOSITION OF ELECTRODE STRIP ON BASE METAL PENETRATION
}

\author{
V.N. MATVIENKO, L.K. LESHCHINSKY and V.A. MAZUR \\ Priazovsky State Technical University \\ 7 Universitetskaya Str., 87500, Mariupol, Ukraine. E-mail: matviyenkovn@mail.ru
}

\begin{abstract}
The paper gives the results of investigation of effect of composition and thermophysical properties of weld pool molten metal on penetration efficiency in submerged arc surfacing using strip electrode. The results of processing and analysis of received experimental and calculation data show that under conditions of formation of composition of weld pool close to strip electrode composition, reduction of penetration area is correlated with reduction of melt enthalpy at replacement of Sv-08kp strip by Sv-12Kh18N10. 8 Ref., 1 Table, 4 Figures.
\end{abstract}

Keywords : metal melting, weld pool, thermophysical properties, enthalpy, melting temperature, surfacing, strip electrode, penetration area

Solving the problem of increase of efficiency and improvement of technical-economical characteristics of arc welding and surfacing, as one of the directions, provides for study of the process of metal heating and formation of weld pool taking into account thermophysical properties of welding consumables.

In strip electrode surfacing the composition and properties of weld pool molten metal are determined by considerably larger portion of electrode metal and significantly lower portion of base one $[1,2]$. At the same time, if section of strip electrode is preserved invariable and current density is linear (relatively to strip width), the portion of electrode metal in the pool melt is determined by the level of heat source dis-

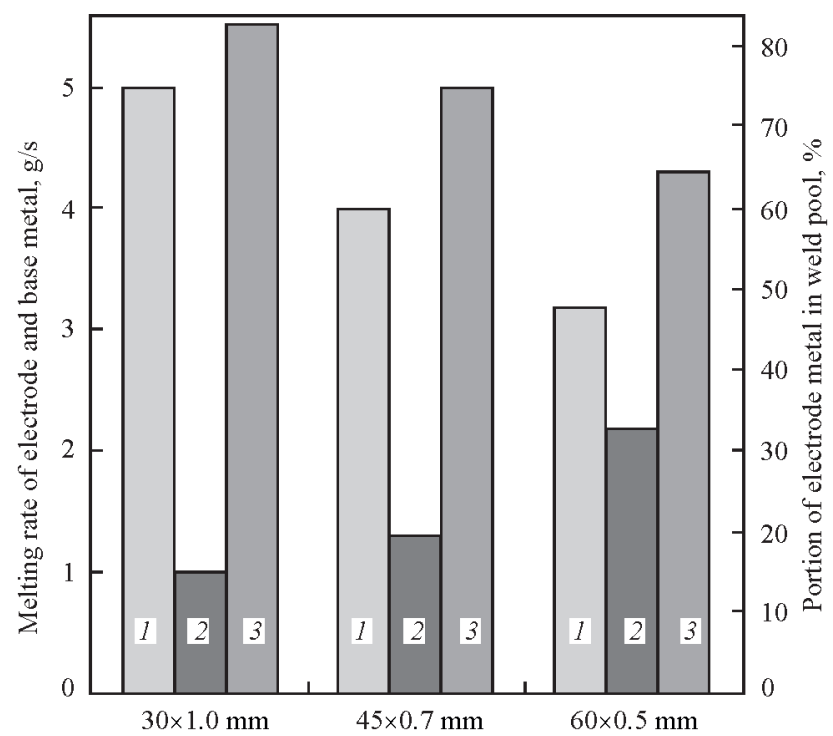

Figure 1. Weight melting rate of electrode (1) and base (2) metal, and portion of electrode metal in composition of weld pool (3) in strip electrode surfacing of different sections tribution and, as follows from the experimental data (Figure 1), depends on strip geometry.

It agrees with the investigations of macrosections of cross-section of deposited beads (Figure 2) as well as calculated shape and size of penetration zone at strip width from 30 to $60 \mathrm{~mm}$ (Figure 3). The calculation data were acquired using mathematical model of the process of base metal heating, based on solving a non-linear differential equation of heat conductance
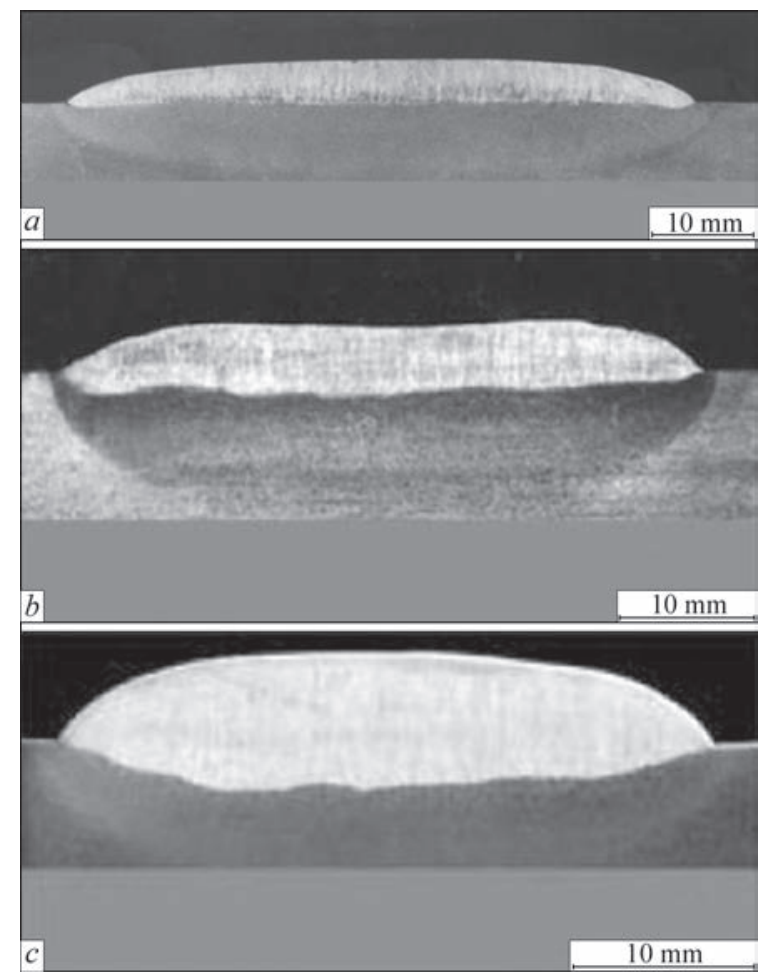

Figure 2. Macrostructure of cross-section of beads in surfacing with strip electrodes of $60 \times 0.5(a), 45 \times 0.7(b)$ and $30 \times 1.0(c) \mathrm{mm}$ section from $12 \mathrm{Kh} 18 \mathrm{~N} 10$ steel 
Effect of composition and thermophysical properties of weld pool melt on relative value of penetration area

\begin{tabular}{|c|c|c|c|c|c|c|c|}
\hline \multirow{2}{*}{ Strip surfacing } & \multirow{2}{*}{$T_{\text {melt, }}{ }^{\circ} \mathrm{C}$} & \multirow{2}{*}{$T_{\text {melt }}^{i} / T_{\text {melt }}^{\mathrm{st}}$} & $\Delta H, \mathrm{~J} / \mathrm{g}$ & $\Delta H^{\mathrm{i} / \Delta H^{\mathrm{st}}}$ & $\Delta H, \mathrm{~J} / \mathrm{g}$ & $\Delta H^{\mathrm{i} / \Delta H^{\mathrm{st}}}$ & \multirow{2}{*}{ Change of penetration area } \\
\hline & & & \multicolumn{2}{|c|}{ Calculation data } & \multicolumn{2}{|c|}{ Experimental } & \\
\hline Sv-08kp & 1530 & 1 & 1130 & 1 & 1450 & 1 & 1 \\
\hline Sv-12Kh18N10 & 1420 & 0.93 & 930 & 0.82 & 1200 & 0.82 & $0.80 / 0.82$ \\
\hline $70 \mathrm{Cu}-30 \mathrm{Ni}$ & 1240 & 0.81 & 710 & 0.62 & - & - & $-/ 0.60$ \\
\hline \multicolumn{8}{|c|}{$\begin{array}{l}\text { Note. } T_{\text {melt }}^{i} / T_{\text {melt }}^{\text {st }}, \Delta H^{i} / \Delta H^{\mathrm{st}}-\text { relation of melting temperature and enthalpy of melt of this material to penetration temperature and en- } \\
\text { thalpy of steel } 08 \mathrm{kp} \text {. Before the slash }- \text { determination of penetration area on macrosections (see Figure } 4 \text { ), after }- \text { results of processing } \\
\text { of data of work [7]. }\end{array}$} \\
\hline
\end{tabular}

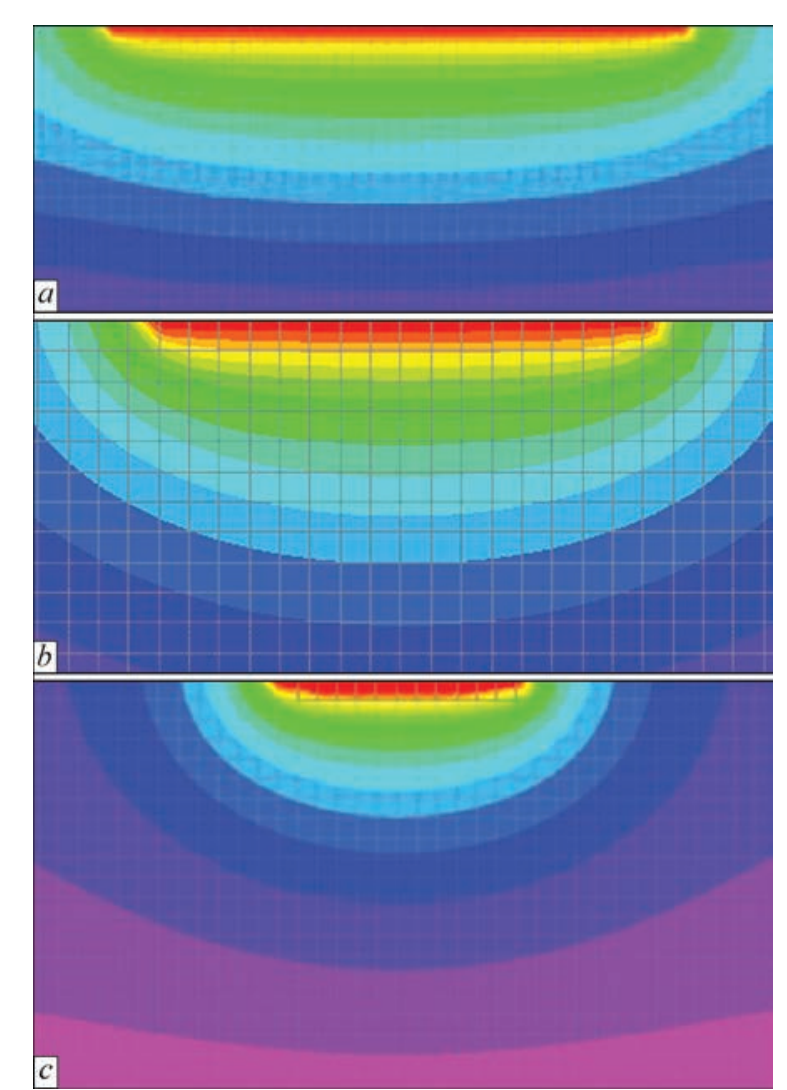

Figure 3. Models of thermal field in plane normal to deposited surface for strip electrodes same as in $a-c$ - the Figure 2

taking into account temperature dependence of thermophysical properties of the material [3].

Portion of electrode metal in the pool achieves $83-85 \%$ (see Figure 1) in surfacing of St. 3 steel with $\mathrm{Sv}-12 \mathrm{Kh} 18 \mathrm{~N} 10$ strip electrode of $60 \times 0.5 \mathrm{~mm}$ section. Such a high portion of electrode metal allows assum-

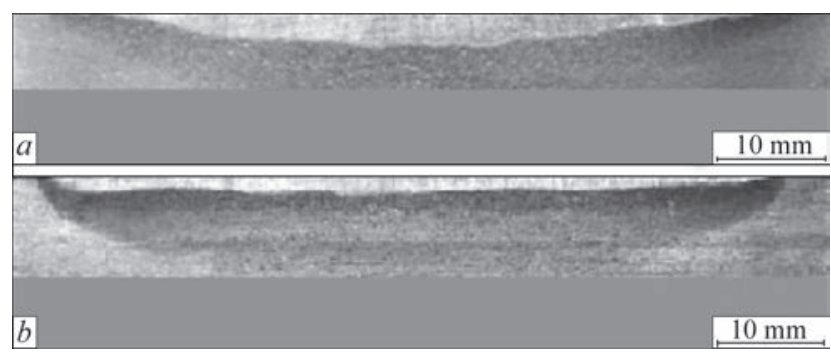

Figure 4. Macrosections of cross-section of penetration zone in surfacing by strip electrodes of $60 \times 0.5 \mathrm{~mm}$ section from steel $08 \mathrm{kp}(a)$ and $12 \mathrm{Kh} 18 \mathrm{~N} 10(b)$ ing that the composition of weld pool is close to the composition of strip electrode.

At the same time, carried investigations showed that the penetration area at constant surfacing mode using strip electrode Sv-12Kh18N10 reduces in comparison with surfacing with strip electrode Sv-08kp. Such effect of the composition of weld pool on geometry of penetration zone is related with heat transfer by convection [4]. Mathematical modelling and experimental investigations allow evaluating the effect of convection currents of molten metal in the pool on shape and size of the penetration zone. At that metal properties [5] are considered as a variable factor. Quantitative evaluation of the portion of heat transfer by convection in the total heat input balance verifies its significance [6].

The heat transfer by convection depends on thermophysical properties of the weld pool molten metal and first of all on enthalpy $\Delta H$ as well as on temperature determining melt flow of the pool. Evaluation of effect of melt enthalpy on efficiency of the base metal penetration in strip electrode surfacing was carried out by analysis of $\Delta H$ values (received experimentally [4] as well as by calculations [7, 8]). They characterize properties of the molten metal in a wide range, i.e. from weld pool temperature $\left(1550-1750{ }^{\circ} \mathrm{C}\right)$ to drop metal transfer temperature $\left(1900-2300{ }^{\circ} \mathrm{C}\right)$.

Carried analysis showed (the Table) that, regardless the difference of absolute values, the relationship of enthalpy of steels $12 \mathrm{Kh} 18 \mathrm{~N} 10$ and $08 \mathrm{kp}$ changes in small ranges. At the same time, determination of the penetration area using macrosections (Figure 4) as well as results of processing of data acquired in work [7] showed that the level of decrease of penetration area is correlated with reduction of enthalpy $\Delta H$ in the case of application of Sv-12Kh18N10 strip electrode instead of Sv-08kp.

If $70 \mathrm{Cu}-30 \mathrm{Ni}$ strip electrode is used (as shown by data processing), then the portion of electrode metal in the pool reaches $92-94 \%$ and enthalpy of the metal 
melt is significantly lower than for steel $12 \mathrm{Kh} 18 \mathrm{~N} 10$, particularly in comparison with steel $08 \mathrm{kp}$. At that, the level of reduction of enthalpy of alloy $70 \mathrm{Cu}-30 \mathrm{Ni}$ in comparison with its value for steel $08 \mathrm{kp} \Delta H^{i} / \Delta H^{\mathrm{st}}$ is also correlated with decrease of penetration area.

\section{Conclusion}

Development of the technology of strip electrode surfacing, when the composition of weld pool is mainly determined by the composition of applied strip, requires consideration of effect of thermophysical properties of molten metal of the pool on penetration efficiency.

1. Ryabtsev, I.A. (2005) High-efficiency wide-layer surfacing using electrode wires and strips (Review). The Paton Welding J., 6, 31-35.
2. Kalensky, V.K. (1999) Specifics and some technological characteristics of electroslag cladding with one electrode strip. Avtomatich. Svarka, 3, 16-21.

3. Matvienko, V.N., Mazur, V.A., Leshchinsky, L.K. (2015) Evaluation of shape and sizes of weld pool in surfacing using combined strip electrode. The Paton Welding J., 9, 28-31.

4. Lavrik, V.P., Leshchinsky, L.K., Pirch, I.I. (1985) Influence of thermophysical properties of strip electrode melt on nature of metal penetration in wide-layer surfacing. Svarochn. Proizvodstvo, 3, 34-35.

5. Bahrami, A., Aidun, D.K. (2012) Modeling of transport phenomena in dissimilar welding of 2205 duplex stainless steel to 1018 carbon steel. In: Proc. of $9^{\text {th }}$ Int. Conf. on Trends in Welding Research, 916-921.

6. Dmitrik, V.V., Shevchenko, V.V. (2001) Effectiveness in use of molten pool heat. The Paton Welding J., 4, 24-26.

7. Oh, Y.K., Davletian, J.H., Chen, S.J. (1990) Low-dilution electroslag cladding for shipbuilding. Welding J., 8, 37-44.

8. Soderstrom, E.J., Scott, K.M., Mendez, P.F. (2011) Calorimetric measurement of droplet temperature in GMAW. Ibid., 4, $77-84$.

Received 28.04.2016 